\title{
A Fuzzy Methodology for Innovation Management Measurement
}

Victor G. Alfaro-García and Anna M. Gil-Lafuente

Facultat d'Economia i Empresa, Universitat de Barcelona, Barcelona, Spain, and

Gerardo G. Alfaro Calderón

\begin{abstract}
Facultad de Contaduría y Ciencias Administrativas, Universidad Michoacana de San Nicolás de Hidalgo, Morelia, Michoacán, Mexico
\end{abstract}

\begin{abstract}
Purpose - Innovation has been recognized as one of the main sources of competitive advantage for organizations and nations. The purpose of this study is to present an innovation management measurement approach applying fuzzy techniques to small and medium manufacturing enterprises.

Design/methodology/approach - This study presents a survey focusing on seven innovation measurement areas: innovation strategy, knowledge management, project management, portfolio management, internal enablers, organization and structure and external enablers. A total of 91 small and medium enterprises (SMEs) located in the city of Morelia, Mexico, participated in the study. Furthermore, the data collected were analyzed under a multi-criteria decision-making approach using the theory of expertons and the induced generalized ordered weighted averaging (IGOWA) operator.
\end{abstract}

Findings - The results show that the most valued areas are innovation strategy, organization and structure, knowledge management and project management. Furthermore, portfolio management, external drivers and internal drivers are the areas with the lowest valuations.

Originality/value - This paper presents an original methodological structure based on an expertise process designed to achieve well-founded results from uncertain and subjective opinions directly from the managers of the surveyed SMEs.

Keywords - Innovation measurement, Fuzzy Analysis, Innovation Management, Theory of expertons, Aggregation operators, Small and medium sized firms.

Paper type - Research paper 


\section{Introduction}

J. Schumpeter (1934) proposed the first study of innovation as a dynamic concept for economic development and economic progress. Since then, a plethora of definitions for innovation have appeared, e.g., the department of trade and industry of the UK defines that innovation is the successful exploitation of new ideas (Branson, 1988), while the Oslo Manual (OECD, 2005) states that innovation is the implementation of a new or significantly improved product (good or service), process, marketing method, or organizational method in business practices, workplace organization or external relations.

Over the past six decades, the literature concerning innovation management has experienced constant evolution (Drejer, 2002; Keupp et al., 2012; Tidd, 2001). Much of the interest centers on the idea that innovation is a driver for competitiveness (see, e.g., Porter, 1990), and some of its positive effects include increases in sales and market share, productivity improvement, and efficiency in operations.

The late 1970s saw the emergence of a focused interest in the study of innovation management in small and medium sized enterprises (SMEs). Increasing attention received by SMEs has been primarily triggered by the dynamism they generate in the countries' economies (Wolff and Pett, 2006), increase in employment rates (Birch, 1989), and especially in their ability to perform remarkable innovations (Fritz, 1989; Keizer et al., 2002). The sustainable introduction of innovations by SMEs strengthens the position of industry and generates profits above the average in the market (Porter, 1980).

An interesting issue in innovation management is its measurement (Gimbert et al., 2010; Simons, 1990). Approximately 40 years ago, only input indicators were analyzed, e.g., spending on research and development (R\&D), number of acquired patents and the amount of highly qualified human resources. Currently, the concept has advanced toward consideration of innovation measurement as a system, e.g., the approach of the holistic framework of innovation management measurement suggested by Adams et al. (2006), the consolidation of theories around innovation and its measurement by Crossan and Apaydin (2010), and the empirical study undertaken by Edison et al., (2013).

The main objective of innovation measurement is to systematically determine whether the resources committed to innovation activities within companies are justified. This allows the revision of a firm's innovation goals and objectives and the most adequate set of incentives for its promotion and management (Cordero, 1990). However, this measurement is complex because there is no single or main trend to assess the extent of 
innovation, plus the information regarding the concept is highly subjective and uncertain (Alfaro-García et al., 2015; Frenkel et al., 2000).

The aim of this paper is to present a methodological structure for the measurement of innovation management in manufacturing SMEs under a fuzzy approach. This is an original methodology that first presents a survey designed to evaluate the opinions of SME managers around the seven key innovation measurement areas proposed by Adams et al. (2006): innovation strategy, knowledge management, project management, portfolio management, internal drivers, organization and structure, and external drivers. The process used to analyze the subjective information retrieved from the survey is a multicriteria decision-making problem employing two models. The first is the theory of expertons (Kaufmann and Gil-Aluja, 1993; Kaufmann, 1988); the main advantage of this tool is the complete consideration of group information, including all of the individual opinions, and the production of a final single result. The second is the application of the induced generalized ordered weighted averaging (IGOWA) operator (Yager, 2004) to aggregate the expertons results. The objective of the IGOWA operator is the aggregation of information considering different degrees of importance to the arguments included in the problem. It has been observed that aggregation operators are useful when there is a need to assess information in a more efficient way than can be accomplished through traditional averaging (Emrouznejad and Marra, 2014).

The article is structured as follows. Section 1 presents the preliminaries of the study, considering the innovation management measurement literature, the theory of expertons and the IGOWA operator. Section 2 discusses the methodology and the results of the survey. Section 3 presents the application of the theory of expertons and IGOWA analysis to our specific problem. Finally, Section 5 summarizes the main conclusions of the article.

\section{Preliminaries}

In this section, we briefly review some basic concepts regarding the innovation management measurement, the theory of expertons and the induced generalized ordered weighted aggregation operator.

\section{Innovation management measurement}

This study takes the proposal developed by Adams et al. (2006) as the primary innovation measurement reference. The framework developed by Adams et al. (2006) is based on a review of six models and frameworks of innovation measurement (Burgelman 
et al., 2009; Chiesa et al., 1996; Cooper and Kleinschmidt, 1995; Cormican and O’Sullivan, 2004; Goffin and Pfeiffer, 1999; Verhaeghe and Kfir, 2002). It should be noted that from the seven main areas outlined by the authors, a framework for measuring innovation has been adapted. This approach, which is based on the theory of dynamic capabilities (Teece et al., 1997; Pavlov and El Sawy, 2011), has been widely adopted to measure, model and describe innovation management performance, e.g., a theoretically based framework for innovation capabilities measurement in SMEs (Saunila, 2016); empirical research of process innovation activities and mechanisms in manufacturing and service firm performance (Piening and Salge, 2015); a four staged multi-dimensional process-based innovation performance measurement scheme (Dewangan and Godse, 2014); and an innovation index to benchmark innovation capabilities in SMEs (Galvez et al., 2013).

The first innovation measurement area (IMA) is innovation strategy in firms. Studies have suggested that inefficiencies in processes can be reduced by maintaining an innovation strategy integrated to the culture, behavior and actions of an organization (O'Brien, 2003). Therefore, when assessing the area of innovation strategy in a firm, it is relevant to analyze factors such as long-term administrative commitment and the direct location of resources toward innovation efforts (Cooper et al., 2004), the link between key business objectives and leadership created by a shared and robust vision along the organizational structure (Pinto and Prescott, 1988), the risk aversion level of the board, and the pro-activity of the direction as well as their persistence and commitment to innovation (Saleh and Wang, 1993). Moreover, empirical studies have demonstrated that appropriate formulation, implementation and monitoring of an innovation strategy for the firm can assure the development of strategic capabilities (Vicente et al., 2015).

The second IMA is knowledge management. This includes the management of explicit and implicit knowledge within organizations (Nonaka, 1991), as well as the process of collection and use of such information. It is therefore worth determining the level of absorptive capacity (AC), understood as the ability to recognize the value of new knowledge from ideas generated within the company (Chiesa et al., 1996; Valentim et al., 2015) or obtained from external connections with other companies or information resources (Atuahene-Gima, 1995; Tipping et al., 1995; Chang et al., 2013), as well as the assimilation and application of knowledge to commercial activities (Cohen and Levinthal, 1990). 
The third IMA considers project management. The literature agrees on the importance of the relationship between innovation and efficiency along with its impact on business performance when managing projects (Spieth and Lerch, 2014). Commonly, such a relationship is measured in terms of cost, duration and return on investment (Adams et al., 2006; Chiesa et al., 1996; Lichtenthaler, 2016). Additionally, it is interesting to know the extent of the internal communication of the implicated areas when developing a new product (Damanpour, 1991), as well as collaboration with suppliers (Bessant, 2003) and customers (Von Hippel, 1986) given their identification as sources that contribute to the innovation process.

The fourth IMA is new product portfolio management. Given the fast changing environment in which SMEs govern their production activities, the effectiveness in which an organization manages its new products portfolio is often a key determinant of competitive advantage (Bard et al., 1988). It is important to know the extent to which firms base their operations on systematized processes that are guided by clear criteria, as doing so facilitates the optimal use of limited resources and improves an organization's competitive position (Hall and Nauda, 1990). Furthermore, highly competitive companies use formal tools applied consistently to all developing projects of a given portfolio (Cooper et al., 1999) and the selection of the product to be developed must be a rational and objective choice based on a systematized path of multi-criteria dimensions (Jugend and Da Silva, 2013).

The fifth IMA includes all internal drivers, which can be defined as entry systems and tools for the innovation process (Adams et al, 2006). According to the literature, internal drivers provide a competitive advantage for companies that use them formally (Bessant and Francis, 1997; Cooper et al., 2004). In that order of ideas, it is important to know and measure the timeliness in which organizations allocate resources (both financial resources and personnel) to product development and the efficiency of that process (Hinckeldeyn et al., 2015)

The organization and structure of the firm is the sixth IMA. It is generally accepted that companies can create work environments that promote the innovation process (Tidd et al., 2001). In that sense, it is necessary to know the intensity with which companies maintain their organizational structure aligned with their project management processes (Pugh et al., 1969); it is also necessary to measure the freedom that workers experience while generating ideas from experimentation, the conception of mistakes as a source of expertise (Anderson and West, 1996; Zien and Buckler, 1997) and the general creativity 
supporting work environment of the firm (Dul and Ceylan, 2014).

The seventh and last IMA are the external drivers. This area measures the intensity with which a company launches its products to the market (Calantone and Benedetto, 1988; Globe et al., 1973), i.e., market research, testing and development adapted to a systematic marketing program (Griffin and Page, 1993). It additionally measures the way firms reach the consumer, formal post-sale operations (Atuahene-Gima, 1995; von Zedtwitz, 2002) and technology and marketing synergy, which has been empirically demonstrated to have an influence on product performance (Huang and Tsai, 2014).

\section{The theory of expertons}

The theory of expertons (Kaufmann and Gil-Aluja, 1993; Kaufmann, 1988) suggests that in order to obtain realistic data from phenomena that are not directly measurable, an aggregated set of valuations given by experts is useful. Note that the experton is a concept issued from theories of fuzzy sets, intervals of confidence and random sets.

An experton is an extension of the probabilistic set (Hirota, 1981), where an interval of probabilities is obtained for each level $\alpha \in[0,1]$ from the valuation of several experts (Kaufmann, 1990). An experton is a generalization of a probabilistic set when cumulative probabilities are replaced by intervals, which decrease monotonically. Moreover, a probabilistic set is a generalization of a fuzzy set, which in turn is a generalization of an ordinary set. Kaufmann (1988), mathematically describes an experton as follows:

Assume $E$ is a referential set, finite or not; $r$ experts are asked to give their own subjective opinion about each element of $E$ by an interval of confidence given by:

$$
\forall x \in E:\left[a_{*}^{j}(x), a_{j}^{*}(x)\right] \subset[0,1]
$$

where $\subset$ is the set inclusion and $j$ is the $j$ th expert.

Then, a statistic that concerns for each $x \in E$ the lower bounds in one way and the upper bound in the other, a cumulative complementary law $F_{*}(a, x)$ is established for the $a_{*}^{j}(x)$ and $F^{*}(a, x)$ is established for the $a_{j}^{*}(x)$. From that process, we obtain:

$$
\forall x \in E, \forall x \in[0,1]: \tilde{A}(x)=\left[F_{*}(a, x), F^{*}(a, x)\right]
$$

where symbol $\sim$ is the nature of the concept. 
The referential set $E$ is the following experton:

$$
\forall x \in E, \forall \alpha \in[0,1]:\left[F_{*}(a, x), F^{*}(a, x)\right]=1
$$

The empty experton is then given by:

$$
\forall x \in E,:\left[F_{*}(a, x), F^{*}(a, x)\right]=\left\{\begin{array}{l}
1, \alpha=0 \\
0, \alpha \neq 0
\end{array}\right.
$$

Finally, the experton can be reduced to a single representative value by decreasing the results' entropy. This process is useful when a final consideration or interpretation of phenomena is needed. In this case, the most common way to reduce the entropy of an experton can be obtained by calculating the mathematical expectation of the probabilistic set.

Expertons ease group decision-making by providing quantitative data retrieved directly from the dialog maintained with several experts surrounding a certain phenomenon. In general, this approach allows an interesting tool for the aggregation of information, unifying different views or expectations of groups with different interests. Moreover, the model allows recognition of the levels of distribution in the aggregate values of the characteristic membership function.

\section{Aggregation operators in decision-making}

The wide range of problems that aggregation operators reach, especially in the areas of economics, statistics and engineering, has generated increasing interest in the literature (Emrouznejad and Marra, 2014). An extensive number of applications with aggregation operators have been proposed (Beliakov et al., 2007; Torra and Narukawa, 2007; Yager et al., 2011).

One of the most common methods is the ordered weighted averaging (OWA) operator (Yager, 1988). This operator aggregates information by establishing a weighting vector that gives a specific degree of importance to the ordered arguments presented in the problem. Since its appearance, the OWA operator has been applied in numerous applications (e.g., Yager and Kacprzyk, 1997)

An interesting generalization of the OWA operator is the induced generalized ordered weighted aggregation (IGOWA) operator (Merigó and Gil-Lafuente, 2009). This 
aggregation operator shares the main characteristics of the OWA operator; the main difference is the introduction of order-induced variables, which generate a new reordering mechanism of the arguments (Yager and Filev, 1999), thus considering higher complexity in the attitudinal characteristics of the decision makers (Chen and Chen, 2003; Wei, 2009; $\mathrm{Xu}, 2006$; Yager, 2003). The IGOWA operator can be defined as follows:

Definition 1. An IGOWA operator of dimension $n$ is a mapping IGOWA: $R^{n} \rightarrow R$, associated with a weighting vector $W$ of dimension $n$ such that $\sum_{j=1}^{n} w_{j}=1, w_{j} \in[0,1]$, a set of order-inducing variables $u_{i}$, and a parameter $\lambda \in(-\infty, \infty)$, following the next formula:

$$
\operatorname{IGOWA}\left(\left\langle u_{1}, a_{1}\right\rangle, \ldots,\left\langle u_{n}, a_{n}\right\rangle\right)=\left(\sum_{j=1}^{n} w_{j} b_{j}^{\lambda}\right)^{1 / \lambda}
$$

where $\left(b_{1}, \ldots, b_{n}\right)$ is $\left(a_{1}, a_{2} \ldots, a_{n}\right)$ reordered in decreasing values of the $u_{i}$. Note that the $u_{i}$ are the order-inducing variables and the $a_{i}$ are the argument variables. It has been demonstrated that the IGOWA operator is commutative, idempotent, bounded and monotonic (Merigó and Gil-Lafuente, 2009).

The IGOWA operator has been applied in financial decision-making processes (Merigó and Gil-Lafuente, 2009; Merigó and Casanovas, 2011), but the parameterized families of the operator, including the window induced generalized ordered weighted aggregation (Window-IGOWA) operator, the olympic induced generalized ordered weighted average (Olimpic-IGOWA) operator, the step induced generalized ordered weighted (S-IGOWA) operator, among others (see Merigó and Gil-Lafuente, 2009), could be employed in diverse fields of knowledge, including engineering, economics, or statistics. In our particular case, we use the IGOWA operator in a multi-criteria decisionmaking problem considering the aggregation of an expert's subjective opinions regarding innovation management.

\section{Methodology}

In this section, we present the methodology employed to develop the survey and the data gathering.

The survey included a total of 32 statements. Each statement can be answered by an endecadary interval of 11 equidistant positions [0,1], with 0 being complete disagreement 
with the statement, and 10 being complete agreement with the suggested statement (see Kaufmann, 1990). Note that all of the statements were selected from previously tested studies in innovation management diagnostics or innovation management audits (Chiesa et al., 1996; CIDEM, 2002). Note also that the 32 questions are categorized in the seven key innovation measurement areas proposed by Adams et al. (2006). The original survey was pilot tested by nine experts in innovation management: three academicians from the Universidad Michoacana de San Nicolás de Hidalgo, two academicians from the University of Barcelona and four local entrepreneurs. Seven responses were retrieved. With that information, the survey was improved.

The goal of the research was to obtain the largest pool of information possible from the manufacturing SMEs located in the city of Morelia, México. To achieve this goal, we revised the national statistical directory of economic units (INEGI, 2015) to find the total number of companies that matched the selected profile. A total of 182 active small and medium sized manufacturing firms were found. Then, a team was created and capacitated with the aim of personally surveying the 182 SMEs; this team included 39 students and three professors. The data were collected from January to July 2015. The intended respondents of the survey were the general managers of the SMEs. If the general manager was not available, then the production manager responded to the survey. From a total of 182 surveyed firms, 91 valid responses were retrieved, i.e., a response rate of 50\%. From those 91 companies that adequately responded to the survey, $78 \%$ are classified as smallsized businesses and $12 \%$ as medium-sized companies. Additionally, general information was collected from participating SMEs, including type of industry, actual size of the organization and electronic address. The general characteristics of the survey are described in Table 1.

Table 1. Characteristics of the Survey

\begin{tabular}{ll}
\hline Characteristic & Value \\
\hline Location & Morelia, México. \\
Time of the survey & January - July 2015 \\
Estimated population* & 182 \\
Sample size & 124 \\
Number of responses & 91 \\
Response rate** & $74 \%$ \\
Confidence level $(\mathrm{p}=\mathrm{q}=0.5)$ & $96 \%$ \\
\hline
\end{tabular}

Source: Self-elaborated.

* Total estimate of registered manufacturing SMEs in the city of Morelia, México. (INEGI, 2015). 
Please note that the sample combines the small and medium sized manufacturing firms. Note also that a small enterprise is characterized as having a minimum of 11 employees and a maximum of 50, while medium sized manufacturing firms are characterized as having a minimum of 51 employees and a maximum of 250 employees (INEGI, 2009). A manufacturing firm is defined as an economic and legal unit under a single proprietary or controlling entity that is primarily engaged in industrial activities for public sales and has an operational structure divided into branches or a single physical location (INEGI, 2010).

\section{Results}

\section{Validation of the survey}

Two statistical analyses were applied to validate the information retrieved from the survey. The first is a reliability analysis describing the properties of the scales used within the survey. The second is a discriminant test to validate the constructed variables.

Of the diverse procedures for conducting reliability analysis (Campbell and Russo, 2001; Carmines and Zeller, 1979), in this study, we applied Cronbach's alpha coefficient of reliability. This test was applied to the 32 statements included in the survey, each of which was characterized in the seven innovation management areas described in Adams et al., 2006. Table 2 shows the results of the reliability test.

Table 2. Cronbach's alpha test results

\begin{tabular}{lcc}
\hline Innovation Management Area & Elements & Cronbach's alpha* \\
\hline 1. Innovation Strategy & 5 & 0.843 \\
2. Knowledge Management & 4 & 0.788 \\
3. Project Management & 5 & 0.825 \\
4. Portfolio Management & 4 & 0.845 \\
5. Internal Drivers & 5 & 0.867 \\
6. Organization and Structure & 4 & 0.779 \\
7. External Drivers & 5 & 0.516
\end{tabular}

Source: Authors calculations based on data collected in fieldwork. $* \mathrm{~N}=91$ Valid cases $(100 \%)$. 
It is widely known that the Cronbach's alpha test evaluates the inter-correlation between the included elements (Hogan, 2004). In our case, the general Cronbach's alpha is 0.911 for all the elements in the survey. Regarding each area, the minimum value obtained is 0.516. Based on the minimum standard values for a Cronbach's test (Rosenthal, 1994), we determined the reliability of the elements included in the survey.

The discriminant validity test is a correlation analysis applied to the seven constructs generated by the 32 statements included in the survey, i.e., the seven IMA. The results with a significance level of $99 \%$ show that no constructs are perfectly correlated, therefore validating the information. Table 3 shows the obtained results.

Table 3. Correlation Analysis

\begin{tabular}{|c|c|c|c|c|c|c|c|}
\hline & $\begin{array}{c}\text { Innovation } \\
\text { Strategy }\end{array}$ & $\begin{array}{l}\text { Knowledge } \\
\text { Management }\end{array}$ & $\begin{array}{c}\text { Project } \\
\text { Management }\end{array}$ & $\begin{array}{l}\text { Portfolio } \\
\text { Management }\end{array}$ & $\begin{array}{l}\text { Internal } \\
\text { Drivers }\end{array}$ & $\begin{array}{c}\text { Organization } \\
\text { and } \\
\text { Structure } \\
\end{array}$ & $\begin{array}{c}\text { External } \\
\text { Drivers }\end{array}$ \\
\hline $\begin{array}{l}\text { Innovation } \\
\text { Strategy }\end{array}$ & - & $.693^{* *}$ & $.655^{* *}$ & $.657^{* *}$ & .666 & $.674^{* *}$ & .577 \\
\hline $\begin{array}{l}\text { Knowledge } \\
\text { Management }\end{array}$ & & - & $.738^{* *}$ & $.719^{* *}$ & .721 & $.649^{* *}$ & .574 \\
\hline $\begin{array}{l}\text { Project } \\
\text { Management }\end{array}$ & & & & $.786^{* *}$ & $\underset{* *}{.767}$ & $.598^{* *}$ & .539 \\
\hline $\begin{array}{l}\text { Portfolio } \\
\text { Management }\end{array}$ & & & & - & .741 & $.707^{* *}$ & .577 \\
\hline $\begin{array}{l}\text { Internal } \\
\text { Drivers }\end{array}$ & & & & & - & $.698^{* *}$ & .634 \\
\hline $\begin{array}{l}\text { Organization } \\
\text { and } \\
\text { Structure } \\
\text { External } \\
\text { Drivers }\end{array}$ & & & & & & - & .563 \\
\hline
\end{tabular}

Source: Authors calculations based on data collected in fieldwork.

** Correlation is significant at the 0.01 level (bilateral)

\section{Fuzzy Analysis}

Once the results of the survey have been validated, we suggest a fuzzy analysis following two procedures. The first is the application of the theory of expertons to generate a single representative value for the opinions of the managers regarding each of the 32 statements included in the survey. The second consists of the calculation of the IGOWA operator to aggregate the results of the expertons into the seven innovation management measurement variables considered in the study. 


\section{Expertons Analysis}

The objective of the experton analysis is the development of a single representative value of the 91 subjective opinions of the SME managers in relation to the 32 statements presented in the survey. The general procedure can be described as the following set of steps:

Step 1.1. From the information obtained in the survey, i.e., the subjective opinion of each manager within the interval $[0,1]$, with 0 being complete disagreement with the statement and 1 being complete agreement with the statement, we construct the expertons. Note that the information could be presented in discrete numbers, intervals, and triplets, among others (Kaufmann and Gil-Aluja, 1993).

Step 1.2. We start by calculating the absolute frequencies, i.e., the number of experts who consider the same value for each statement of the survey. Next, we calculate the relative frequencies, i.e., divide the absolute frequencies by the total number of experts. Finally, we generate the accumulated relative frequencies (we sum from $\alpha=1$, the relative frequencies in an accumulated way until $\alpha=0$ ) (Kaufmann, 1988; Kaufmann $\&$ Gil-Aluja, 1993). The result is the experton for each $\alpha$ level.

Step 1.3. Once all of the opinions are aggregated, we need to calculate the expected value of the expertons. The $E V$ is obtained by the addition of all levels of membership $\alpha$, except 0 , and dividing the result by 10 . Following these steps, Tables $4-10$ show the experton analysis results for the surveyed manufacturing SMEs.

Table 4. Expertons results for innovation strategy

\begin{tabular}{cccccc}
\hline Expertons & Statement 1.1 & Statement 1.2 & Statement 1.3 & Statement 1.4 & Statement 1.5 \\
\hline 0.0 & 1.00 & 1.00 & 1.00 & 1.00 & 1.00 \\
0.1 & 1.00 & 1.00 & 1.00 & 1.00 & 1.00 \\
0.2 & 1.00 & 1.00 & 1.00 & 1.00 & 1.00 \\
0.3 & 0.95 & 0.95 & 0.96 & 0.96 & 0.92 \\
0.4 & 0.95 & 0.95 & 0.96 & 0.96 & 0.92 \\
0.5 & 0.82 & 0.84 & 0.70 & 0.86 & 0.74 \\
0.6 & 0.82 & 0.84 & 0.70 & 0.86 & 0.74 \\
0.7 & 0.52 & 0.53 & 0.46 & 0.56 & 0.43 \\
0.8 & 0.52 & 0.53 & 0.46 & 0.56 & 0.43 \\
0.9 & 0.22 & 0.26 & 0.22 & 0.22 & 0.14 \\
1.0 & 0.22 & 0.26 & 0.22 & 0.22 & 0.14 \\
Expected & 0.70 & 0.71 & 0.67 & 0.72 & 0.65 \\
Value & & & & &
\end{tabular}


Table 5. Expertons results for knowledge management

\begin{tabular}{ccccc}
\hline Expertons & Statement 2.1 & Statement 2.2 & Statement 2.3 & Statement 2.4 \\
\hline 0.0 & 1.00 & 1.00 & 1.00 & 1.00 \\
0.1 & 1.00 & 1.00 & 1.00 & 1.00 \\
0.2 & 1.00 & 1.00 & 1.00 & 1.00 \\
0.3 & 0.95 & 0.98 & 0.91 & 0.88 \\
0.4 & 0.95 & 0.98 & 0.91 & 0.88 \\
0.5 & 0.77 & 0.84 & 0.69 & 0.64 \\
0.6 & 0.77 & 0.84 & 0.69 & 0.64 \\
0.7 & 0.49 & 0.64 & 0.44 & 0.36 \\
0.8 & 0.49 & 0.64 & 0.44 & 0.36 \\
0.9 & 0.26 & 0.35 & 0.10 & 0.12 \\
1.0 & 0.26 & 0.35 & 0.10 & 0.12 \\
Expected & 0.69 & 0.76 & 0.63 & 0.60 \\
Value & & & &
\end{tabular}

Table 6. Expertons results for project management

\begin{tabular}{cccccc}
\hline Expertons & Statement 3.1 & Statement 3.2 & Statement 3.3 & Statement 3.4 & Statement 3.5 \\
\hline 0.0 & 1.00 & 1.00 & 1.00 & 1.00 & 1.00 \\
0.1 & 1.00 & 0.99 & 1.00 & 1.00 & 1.00 \\
0.2 & 1.00 & 0.99 & 1.00 & 1.00 & 1.00 \\
0.3 & 0.86 & 0.87 & 0.90 & 0.97 & 0.80 \\
0.4 & 0.86 & 0.87 & 0.90 & 0.97 & 0.80 \\
0.5 & 0.67 & 0.73 & 0.70 & 0.87 & 0.60 \\
0.6 & 0.67 & 0.73 & 0.70 & 0.87 & 0.60 \\
0.7 & 0.44 & 0.40 & 0.53 & 0.52 & 0.32 \\
0.8 & 0.44 & 0.40 & 0.53 & 0.52 & 0.32 \\
0.9 & 0.22 & 0.16 & 0.21 & 0.16 & 0.14 \\
1.0 & 0.22 & 0.16 & 0.21 & 0.16 & 0.14 \\
Expected & 0.64 & 0.63 & 0.67 & 0.70 & 0.57 \\
Value & & & & &
\end{tabular}


Table 7. Expertons results for portfolio management

\begin{tabular}{ccccc}
\hline Expertons & Statement 4.1 & Statement 4.2 & Statement 4.3 & Statement 4.4 \\
\hline 0.0 & 1.00 & 1.00 & 1.00 & 1.00 \\
0.1 & 1.00 & 1.00 & 1.00 & 1.00 \\
0.2 & 1.00 & 1.00 & 1.00 & 1.00 \\
0.3 & 0.86 & 0.81 & 0.89 & 0.82 \\
0.4 & 0.86 & 0.81 & 0.89 & 0.82 \\
0.5 & 0.65 & 0.55 & 0.74 & 0.71 \\
0.6 & 0.65 & 0.55 & 0.74 & 0.71 \\
0.7 & 0.35 & 0.33 & 0.31 & 0.47 \\
0.8 & 0.35 & 0.33 & 0.31 & 0.47 \\
0.9 & 0.12 & 0.14 & 0.10 & 0.18 \\
1.0 & 0.12 & 0.14 & 0.10 & 0.18 \\
Expected & 0.60 & 0.57 & 0.61 & 0.64 \\
Value & & & &
\end{tabular}

Table 8. Expertons results for internal drivers

\begin{tabular}{cccccc}
\hline Expertons & Statement 5.1 & Statement 5.2 & Statement 5.3 & Statement 5.4 & Statement 5.5 \\
\hline 0.0 & 1.00 & 1.00 & 1.00 & 1.00 & 1.00 \\
0.1 & 1.00 & 1.00 & 1.00 & 0.99 & 0.99 \\
0.2 & 1.00 & 1.00 & 1.00 & 0.99 & 0.99 \\
0.3 & 0.69 & 0.81 & 0.93 & 0.93 & 0.79 \\
0.4 & 0.69 & 0.81 & 0.93 & 0.93 & 0.79 \\
0.5 & 0.51 & 0.63 & 0.69 & 0.76 & 0.65 \\
0.6 & 0.51 & 0.63 & 0.69 & 0.76 & 0.65 \\
0.7 & 0.25 & 0.37 & 0.46 & 0.41 & 0.40 \\
0.8 & 0.25 & 0.37 & 0.46 & 0.41 & 0.40 \\
0.9 & 0.12 & 0.19 & 0.18 & 0.19 & 0.12 \\
1.0 & 0.12 & 0.19 & 0.18 & 0.19 & 0.12 \\
Expected & 0.51 & 0.60 & 0.65 & 0.65 & 0.59 \\
Value & & & & &
\end{tabular}


Table 9. Expertons results for organization and structure

\begin{tabular}{ccccc}
\hline Expertons & Statement 6.1 & Statement 6.2 & Statement 6.3 & Statement 6.4 \\
\hline 0.0 & 1.00 & 1.00 & 1.00 & 1.00 \\
0.1 & 0.99 & 0.99 & 0.99 & 0.99 \\
0.2 & 0.99 & 0.99 & 0.99 & 0.99 \\
0.3 & 0.87 & 0.79 & 0.90 & 0.91 \\
0.4 & 0.87 & 0.79 & 0.90 & 0.91 \\
0.5 & 0.62 & 0.68 & 0.76 & 0.79 \\
0.6 & 0.62 & 0.68 & 0.76 & 0.79 \\
0.7 & 0.38 & 0.49 & 0.56 & 0.57 \\
0.8 & 0.38 & 0.49 & 0.56 & 0.57 \\
0.9 & 0.19 & 0.31 & 0.32 & 0.22 \\
1.0 & 0.19 & 0.31 & 0.32 & 0.22 \\
Expected & & & & 0.70 \\
Value & 0.61 & 0.65 & 0.71 & \\
\hline
\end{tabular}

Table 10. Expertons results for external drivers

\begin{tabular}{cccccc}
\hline Expertons & Statement 7.1 & Statement 7.2 & Statement 7.3 & Statement 7.4 & Statement 7.5 \\
\hline 0.0 & 1.00 & 1.00 & 1.00 & 1.00 & 1.00 \\
0.1 & 0.99 & 0.99 & 0.99 & 0.99 & 0.99 \\
0.2 & 0.99 & 0.99 & 0.99 & 0.99 & 0.99 \\
0.3 & 0.92 & 0.88 & 0.88 & 0.92 & 0.90 \\
0.4 & 0.92 & 0.88 & 0.88 & 0.92 & 0.90 \\
0.5 & 0.76 & 0.74 & 0.73 & 0.79 & 0.71 \\
0.6 & 0.76 & 0.74 & 0.73 & 0.79 & 0.71 \\
0.7 & 0.42 & 0.49 & 0.46 & 0.63 & 0.49 \\
0.8 & 0.42 & 0.49 & 0.46 & 0.63 & 0.49 \\
0.9 & 0.11 & 0.19 & 0.22 & 0.34 & 0.19 \\
1.0 & 0.11 & 0.19 & 0.22 & 0.34 & 0.19 \\
Expected & & & & & 0.66 \\
Value & 0.64 & 0.66 & 0.65 & 0.73 &
\end{tabular}




\section{IGOWA analysis}

Once we obtained the expected value for all of the expertons, the next step is the application of an aggregation operator. This calculation allows us to generate overall results for the seven innovation management areas (Adams et al., 2006): innovation strategy, knowledge management, project management, portfolio management, internal drivers, organization and structure and external drivers.

For our specific problem, we choose the IGOWA operator (Merigó and Gil-Lafuente, 2009). The main advantage of this operator is the aggregation of information considering a highly complex attitudinal character from the decision makers, which in the case of innovation management is greatly required. The steps to generate the aggregation using the IGOWLA operator can be described as follows:

Step 2.1. We first need to describe the parameters to be introduced in the aggregation process. In our case, we choose the parameter $\lambda=-3$. Table 11 presents the collective weights $W_{j}$ assigned to the ordering of the arguments. Because of the complex attitude of the decision makers, Table 12 presents a set of $u_{i}$ order-induced variables that take part in the reordering mechanism. Note that in our case, vectors $W_{j}$ and $u_{i}$ are set by the preferences of five experts in the areas of public policy. The primary intention is to have a closer approach to the specific environment of the city and the surveyed SMEs.

Table 11. Collective weights $W_{j}$

\begin{tabular}{lccccc}
\hline & $w_{1}$ & $w_{2}$ & $w_{3}$ & $w_{4}$ & $w_{5}$ \\
\hline 1. Innovation Strategy & 0.30 & 0.10 & 0.40 & 0.15 & 0.05 \\
2. Knowledge Management & 0.40 & 0.30 & 0.20 & 0.10 & \\
3. Project Management & 0.15 & 0.30 & 0.40 & 0.10 & 0.05 \\
4. Portfolio Management & 0.30 & 0.10 & 0.20 & 0.40 & \\
5. Internal Drivers & 0.05 & 0.4 & 0.1 & 0.15 & 0.3 \\
6. Organization and Structure & 0.4 & 0.3 & 0.2 & 0.1 & 0.05 \\
7. External Drivers & 0.30 & 0.15 & 0.10 & 0.40 & 0.10 \\
\hline & & Source: Collected from expert opinions.
\end{tabular}

Table 12. Induced variables $u_{i}$

\begin{tabular}{lccccc}
\hline & $u_{1}$ & $u_{2}$ & $u_{3}$ & $u_{4}$ & $u_{5}$ \\
\hline 1. Innovation Strategy & 4 & 7 & 2 & 1 & 8 \\
2. Knowledge Management & 7 & 4 & 5 & 6 & \\
3. Project Management & 1 & 7 & 2 & 3 & 5 \\
4. Portfolio Management & 2 & 3 & 4 & 1 & \\
5. Internal Drivers & 7 & 5 & 3 & 2 & 8 \\
6. Organization and Structure & 2 & 5 & 1 & 3 & \\
7. External Drivers & 7 & 1 & 2 & 5 & 4 \\
\hline
\end{tabular}


Step 2.2. Calculate the operator following the formulation of the IGOWA operator by Eq. 5 and the information from step 2.1. Figure 1 presents the results for our specific problem.

Figure 1. IGOWA results

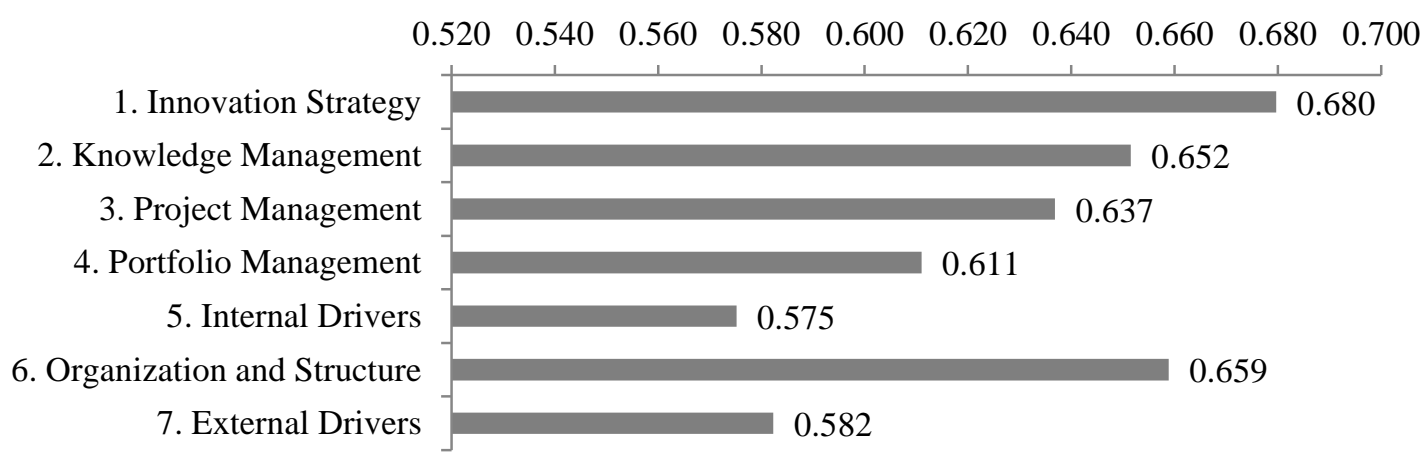

Step 2.3. Generate a ranking of the aggregated results. In our case, we can observe that:

1. innovation strategy $>6$.organization and structure

$>2$. knowledge management $>3$. project management

$>$ 4. portfolio management $>$ 7. external drivers

$>$ 5. internal drivers

Note that the symbol $>$ means preferred in our case.

It is interesting to note that the results could be extended; however, they are subject to specific conditions. The first is the environment in which the managers of the SMEs operate, and the second is the specificities of the variables utilized in the methodological approach, i.e., the characteristics of the IGOWA operator.

\section{Conclusions}

In this paper, we present a methodological structure for innovation management measurement under a fuzzy approach. We collect data from a survey based on one of the latest innovation management frameworks and treat it using the theory of expertons and the IGOWLA operator. The main advantage of this approach is the expertise process, which is designed to work with uncertain and subjective opinions directly from the 
managers (experts) of the surveyed SMEs. We especially note that the flexibility of the parameters allows an accurate interpretation based on the specific conditions of the problem.

A total of 91 SMEs participated in this analysis. The survey presented 32 statements regarding the seven key innovation management measurement areas proposed by Adams et al., (2006). The results conclude that innovation strategy, organization and structure, knowledge management and project management are the most valued areas. On the other hand, portfolio management, external drivers and internal drivers are the areas with the lowest values. These results present a first approach to understanding the complex process of innovation management in the location and could be used for further analysis and policy decision-making processes.

From a managerial perspective, diverse reasons justify the need for assessing the measurement of innovation capabilities in SMEs. In a highly changing environment, the correct evaluation of companies' capabilities to introduce and maintain continuous change can signify competitive advantages in terms of cost reduction, increment on products' life cycles, increment in sales and a global market perspective. The dynamic capabilities' based view of this research also has implications for academia - first by introducing tools for the treatment of uncertainty in the field of innovation management measurement and second by assessing an empiric study of innovation management measurement frameworks that considers a broad perspective of the latest studies' key performance measurement areas.

There are several limitations to this study. One is the focused perspective used in the survey, specifically the statements that need broadening in order to obtain a better understanding of the insights of innovation management. Another limitation is the dynamism of the environment, which requires exploration in several points of time to generate accurate results. Finally, the surveyed companies were treated with the same level of importance; however, they cannot always apply to innovation management, as there are several factors that could affect the performance of highly innovative firms that need to be properly examined.

Further investigation needs to be conducted, both to minimize the observed limitations but also to improve the decision-making process by adding new tools for the treatment of subjective and uncertain information, e.g., the inclusion of interval numbers (Moore, 1966), fuzzy numbers or linguistic variables (Durbach and Stewart, 2012). Other examples include uncertain aggregation operators (Merigó et al., 2014), such as the 
uncertain generalized weighted average (UGWA) operator, the probabilistic weighted average (PWA) operator, and the uncertain generalized probabilistic weighted average (UGPWA), among others. The main focus for future research should be the highly changing environment of the information regarding innovation management; however, the inclusion of the latest approaches in decision-making under uncertainty can shed some light on the way we treat and understand the complexity of innovation.

\section{References}

Adams, R., Bessant, J. and Phelps, R. (2006), "Innovation management measurement: A review”, International Journal of Management Reviews, Vol. 8 No. 1, pp. 21-47.

Alfaro-García, V.G., Gil-Lafuente, A.M. and Alfaro-Calderón, G.G. (2015), “A fuzzy logic approach towards innovation measurement.", Global Journal of Business Research, Vol. 9 No. 3, pp. 53-71.

Anderson, N. and West, M.A. (1996), "The team climate inventory: Development of the tci and its applications in teambuilding for innovativeness", European Journal of Work and Organizational Psychology, Vol. 5 No. 1, pp. 53-66.

Atuahene-Gima, K. (1995), “An exploratory analysis of the impact of market orientation on new product performance a contingency approach", Journal of Product Innovation Management, Vol. 12 No. 4, pp. 275-293.

Bard, J.F., Balachandra, R. and Kaufmann, P.E. (1988), “An interactive approach to R\&D project selection and termination", IEEE Transactions on Engineering Management, Vol. 35 No. 3, pp. 139-146.

Beliakov, G., Pradera, A. and Calvo, T. (2007), Aggregation Functions: A Guide for Practitioners, Vol. 221, Springer Berlin, Heidelberg.

Bessant, J. (2003), High-Involvement Innovation: Building and Sustaining Competitive Advantage through Continuous Change, Recherche, Vol. 67.

Bessant, J. and Francis, D. (1997), "Implementing the new product development process", Technovation, Vol. 17 No. 4, pp. 189-222.

Birch, D.L. (1989), "Change, innovation, and job generation”, Journal of Labor Research, Vol. 10 No. 1, pp. 33-38.

Branson, R. (1988), An Audience with Innovation: Innovation in Management., Great Britain, Department of Trade and Industry.

Burgelman, R.A., Christensen, C.M. and Wheelwright, S.C. (2009), Strategic Management of Technology and Innovation, The Irwin Series in Management and 
the Behavioral Sciences, Vol. 4.

Calantone, R.J.R.J. and Benedetto, C.A. di. (1988), “An integrative model of the new product development process An empirical validation", Journal of Product Innovation Management, Vol. 5 No. 3, pp. 201-215.

Campbell, D. and Russo, M. (2001), Social Measurement, SAGE Publications, Inc., 2455 Teller Road, Thousand Oaks California 91320 United States of America.

Carmines, E. and Zeller, R. (1979), Reliability and Validity Assessment, Vol. 9, SAGE Publications, Inc., California.

Chang, S., Gong, Y., Way, S.A. and Jia, L. (2013), "Flexibility-Oriented HRM Systems, Absorptive Capacity, and Market Responsiveness and Firm Innovativeness", Journal of Management, Vol. 39 No. 7. pp. 1924-1951.

Chen, S.J. and Chen, S.M. (2003), “A new method for handling multicriteria fuzzy decision-making problems using FN-IOWA operators", Cybernetics and Systems, Vol. 34 No. 2, pp. 109-137.

Chiesa, V., Coughlan, P. and Voss, C.A. (1996), "Development of a technical innovation audit”, Journal of Product Innovation Management, Vol. 13 No. 2, pp. 105-136.

CIDEM. (2002), Guide for Managing Innovation: Part 1, Diagnosis, Part 1, edited by Catalunya, G. de and CIDEM, Barcelona, Catalunya.

Cohen, W.M. and Levinthal, D.A. (1990), “Absorptive Capacity: A New Perspective on Learning and Innovation”, Administrative Science Quarterly, Vol. 35 No. 1, p. 128. Cooper, R. and Kleinschmidt, E. (1995), "Benchmarking the firm's critical success factors in new product development", Journal of Product Innovation Management.

Cooper, R.G., Edgett, S.J. and Kleinschmidt, E.J. (1999), "New product portfolio management: practices and performance", Journal of Product Innovation Management, Vol. 16 No. 4, pp. 333-351.

Cooper, R.G., Edgett, S.J. and Kleinschmidt, E.J. (2004), "Benchmarking best NPD practices-I", Research Technology Management, Vol. 47 No. 3, pp. 50-59.

Cordero, R. (1990), "The measurement of innovation performance in the firm: An overview", Research Policy, Vol. 19 No. 2, pp. 185-192.

Cormican, K. and O'Sullivan, D. (2004), “Auditing best practice for effective product innovation management", Technovation, Vol. 24 No. 10, pp. 819-829.

Crossan, M.M. and Apaydin, M. (2010), "A multi-dimensional framework of organizational innovation: A systematic review of the literature", Journal of Management Studies, Vol. 47 No. 6, pp. 1154-1191. 
Damanpour, F. (1991), "Organizational Innovation: a Meta-Analysis of Effects of Determinants and Moderators.", Academy of Management Journal, Vol. 34 No. 3, pp. 555-590.

Dewagan, V. and Godse, M. (2014), "Towards a holistic enterprise innovation performance measurement system", Technovation, Vol. 34 No. 9, pp. 536-545.

Drejer, A. (2002), "Situations for innovation management: towards a contingency model”, European Journal of Innovation Management, Vol. 5 No. 1, pp. 4-17.

Dul, J. and Ceylan, C. (2014), "The Impact of a Creativity-supporting Work Environmenton a Firm's Product Innovation Performance", Product Development \& Management Association, Vol. 31 No. 6, pp. 1254-1267.

Durbach, I.N. and Stewart, T.J. (2012), "Modeling uncertainty in multi-criteria decision analysis”, European Journal of Operational Research, Vol. 223 No. 1, pp. 1-14.

Edison, H., bin Ali, N. and Torkar, R. (2013), "Towards innovation measurement in the software industry", Journal of Systems and Software, Vol. 86 No. 5, pp. 1390-1407.

Emrouznejad, A. and Marra, M. (2014), “Ordered weighted averaging operators 19882014: A citation-based literature survey", International Journal of Intelligent Systems, Vol. 29 No. 11, pp. 994-1014.

Frenkel, A., Maital, S. and Grupp, H. (2000), "Measuring dynamic technical change: a technometric approach”, International Journal of Technology Management, Vol. 20 No. 3/4, p. 429.

Fritz, W. (1989), “Determinants of Product Innovation Activities”, European Journal of Marketing, Vol. 23 No. 10, pp. 32-43.

Galvez, D., Camargo, M., Rodriguez, J. and Morel, L. (2013), "PII-Potential Innovation Index: a Tool to Benchmark Innovation Capabilities in International Context", Journal of Technology Management and Innovation, Vol. 8 No. 4, pp. 36-45.

Gimbert, X., Bisbe, J. and Mendoza, X. (2010), "The role of performance measurement systems in strategy formulation processes", Long Range Planning, Vol. 43 No. 4, pp. 477-497.

Globe, S., Levy, G.W. and Schwartz, C.M. (1973), "Key factors and events int he innovation process", Research Management, Vol. 16, pp. 8-15.

Goffin, K. and Pfeiffer, R. (1999), Innovation Management in UK and German Manufacturing Companies., Anglo-German Foundation.

Griffin, A. and Page, A.L. (1993), “An interim report on measuring product development success and failure", Journal of Product Innovation Management, Vol. 10 No. 4, pp. 
291-308.

Hall, D.L. and Nauda, A. (1990), “An Interactive Approach for Selecting IR\&D Projects”, IEEE Transactions on Engineering Management, Vol. 37 No. 2, pp. 126133.

Von Hippel, E. (1986), “Lead users: An important Source of Novel Product Concepts", Management Science, Vol. 32 No. 7, pp. 791-805.

Hinckeldeyn, J., Dekkers, R. and Kreutzfeldt J. (2015), "Productivity of product design and engineering processes", International Journal of Operations \& Production Management, Vol. 35 No. 4 pp. 458 - 486.

Hirota, K. (1981), “Concepts of probabilistic sets”, Fuzzy Sets and Systems, Vol. 5 No. 1, pp. 31-46.

Hogan, T. (2004), Pruebas Psicologicas: Una Introducción Práctica, Manual Moderno, Mexico City.

Huang C. and Tsai K. (2014), "Synergy, environmental context, and new product performance: A review based on manufacturing firms", Industrial Marketing Management, Vol. 43 No. 8, pp. 1407-1419.

INEGI. (2009), Las Empresas En Los Estados Unidos Mexicanos : Censos Económicos 2009, Mexico City, c2009.

INEGI. (2010), Resultados de Los Módulos de Innovación Tecnológica : MIT 2008, 2006 Y 2001, Mexico City, c2010.

INEGI. (2015), “Directorio Estadístico Nacional de Unidades Económicas”, available at: http://www3.inegi.org.mx/sistemas/mapa/denue/default.aspx (Last accesed November 2015).

Jugend, D. and Da Silva, S.L. (2013), "Product-portfolio management: A framework based on Methods, Organization, and Strategy", Concurrent Engineering, Vol. 22 No. 1, pp. 17-28.

Kaufmann, A. (1988), "Theory of expertons and fuzzy logic", Fuzzy Sets and Systems, Vol. 28 No. 3, pp. 295-304.

Kaufmann, A. and Gil-Aluja, J. (1993), Técnicas Especiales Para La Gestión de Expertos, edited by Milladoiro.

Kaufmann, A.J. (1990). "Expert appraisements and counter-appraisements with experton processes" Proceedings. First International Symposium on Uncertainty Modeling and Analysis, IEEE Comput. Soc. Press, pp. 619-624.

Keizer, J.A., Dijkstra, L. and Halman, J.I.M. (2002), “Explaining innovative efforts of 
SMEs.", Technovation, Vol. 22 No. 1, pp. 1-13.

Keupp, M.M., Palmié, M. and Gassmann, O. (2012), “The Strategic Management of Innovation: A Systematic Review and Paths for Future Research”, International Journal of Management Reviews, Vol. 14 No. 4, pp. 367-390.

Lichtenthaler, U. (2016),"Toward an innovation-based perspective on company performance", Management Decision, Vol. 54 No. 1, pp. 66 - 87

Merigó, J.M., Casanovas, M. and Yang, J.B. (2014), “Group decision making with expertons and uncertain generalized probabilistic weighted aggregation operators", European Journal of Operational Research, Vol. 235 No. 1, pp. 215-224.

Merigó, J.M. and Gil-Lafuente, A.M. (2009), “The induced generalized OWA operator”, Information Sciences, Vol. 179 No. 6, pp. 729-741.

Merigó, J.M. and Casanovas, M. (2011), "Decision-making with distance measures and induced aggregation operators", Computers and Industrial Engineering, Vol. 60 No. 1, pp. 66-76.

Moore, R.E. (1966), Interval Analysis, 4th ed., Prentice-Hall., Englewood Cliffs.

Nonaka, I. (1991), “The Knowledge Creating Company”, Harvard Business Review, Vol. 69, pp. p96-104.

O'Brien, J.P. (2003), “The capital structure implications of pursuing a strategy of innovation”, Strategic Management Journal, Vol. 24 No. 5, pp. 415-431.

OECD. (2005), OSLO Manual: Guidelines for Collecting and Interpreting Innovation Data., Oslo Manual, Vol. 3.

Pavlov, P.A. and El Sawy, O.A. (2011), "Understanding the Elusive Black Box of Dynamic Capabilities", Decision Sciences Journal, Vol. 42 No. 1, pp. 239-273.

Piening, E.P. and Salge, T.O. (2015), "Understanding the antecedents, contingencies, and performance implications of process innovation: A dynamic capabilities perspective", Journal of Product Innovation Management, Vol. 32 No. 1, pp. 80-97. Pinto, J.K. and Prescott, J.E. (1988), "Variations in Critical Success Factors Over the Stages in the Project Life Cycle", Journal of Management, Vol. 14 No. 1, pp. 5-18. Porter, M.E. (1980), “Competitive Strategy: Techniques for Analyzing Industries and Competitors", Competitive Strategy, Vol. 1 No. 6, p. 396.

Porter, M.E. (1990), “The Competitive Advantage of Nations. (cover story)”, Harvard Business Review, Vol. 68, pp. 73-93.

Pugh, D.S., Hickson, D.J., Hinings, C.R. and Turner, C. (1969), "The Context of Organization Structures", Administrative Science Quarterly, pp. 91-114. 
Rosenthal, R. (1994), "Parametric measures of effect size.”, The Handbook of Research Synthesis, pp. 231-244.

Saleh, S.D. and Wang, C.K. (1993), “The management of innovation: strategy, structure, and organizational climate", IEEE Transactions on Engineering Management, Vol. 40 No. 1, pp. 14-21.

Saunila, M. (2016), "Performance measurement approach for innovation capability in SMEs", International Journal of Productivity and Performance Management, Vol. 65 No. 2 pp. 162 - 176.

Schumpeter, J. (1934), "The Theory of Economic Development", Joseph Alois Schumpeter, pp. 61-116.

Simons, R. (1990), "The role of management control systems in creating competitive advantage: New perspectives", Accounting, Organizations and Society, Vol. 15 No. 1-2, pp. 127-143.

Spieth, P. and Lerch, M. (2014), "Augmenting innovation project portfolio management performance: the mediating effect of management perception and satisfaction", $R \& D$ Management, Vol. 44 No. 5, pp. 498-515.

Teece, D.J., Pisano, G., and Shuen, A. (1997), "Dynamic Capabilities and Strategic Management", Strategic Management Journal, Vol. 18 No. 7, pp. 509-533.

Tidd, J. (2001), "Innovation management in context: environment, organization and performance", International Journal of Management Reviews, Vol. 3 No. 3, pp. $169-183$.

Tidd, J., Bessant, J., and Pavitt, K. (2001), "Managing Innovation - Integrating Technological, Market and Organizational Change”, Managing Innovation: Integrating Technological, Market and Organizational Change.

Tipping, J.W., Zeffren, E. and Fusfeld, A.R. (1995), "Assessing the value of your technology", Research-Technology Management, Vol. 38 No. 5, pp. 22-39.

Torra, V. and Narukawa, Y. (2007), Modeling Decisions, Springer Berlin, Heidelberg.

Valentim, L., Veríssimo J. and Franco, M. (2015), "Knowledge management practices and absorptive capacity in small and medium-sized enterprises: is there really a linkage?", R\&D Management, Vol. 46 No. 4, pp. 711-725.

Vicente, M., Abrantes J.L. and Teixera, M.S. (2015), "Measuring innovation capability in exporting firms: the INNOVSCALE", International Marketing Review, Vol. 32 No. 1 pp. $29-51$.

Verhaeghe, a and Kfir, R. (2002), "Managing innovation in a knowledge intensive 
technology organisation (KITO)", R\&D Management, Vol. 32 No. 5, pp. 409-417.

Wei, G.-W. (2009), "Uncertain Linguistic Hybrid Geometric Mean Operator and Its Application To Group Decision Making Under Uncertain Linguistic Environment”, International Journal of Uncertainty, Fuzziness and Knowledge-Based Systems, Vol. 17 No. 2, pp. 251-267.

Wolff, J. a and Pett, T.L. (2006), "Small-firm performance: Modeling the role of product and process improvements", Journal of Small Business Management, Vol. 44 No. 2, pp. 268-284.

$\mathrm{Xu}, \mathrm{Z}$. (2006), "Induced uncertain linguistic OWA operators applied to group decision making”, Information Fusion, Vol. 7 No. 2, pp. 231-238.

Yager, R.R. (1988), “On Ordered Weighted Averaging Aggregation Operators in Multicriteria Decisionmaking", IEEE Transactions on Systems, Man and Cybernetics, Vol. 18 No. 1, pp. 183-190.

Yager, R.R. (2003), "Induced aggregation operators”, Fuzzy Sets and Systems, Vol. 137 No. 1, pp. 59-69.

Yager, R.R. (2004), “Generalized OWA Aggregation Operators”, Fuzzy Optimization and Decision Making, Vol. 3 No. 1, pp. 93-107.

Yager, R.R. and Kacprzyk, J. (Eds.). (1997), The Ordered Weighted Averaging Operators, Springer US, Boston, MA.

Yager, R.R. and Filev D.P. (1999), "Induced ordered weighted averaging operators", IEEE Transactions on Systems, Man, and Cybernetics, Part B (Cybernetics), Vol. 29 No. 2, pp. 141-150.

Yager, R.R., Kacprzyk, J. and Beliakov, G. (Eds.). (2011), Recent Developments in the Ordered Weighted Averaging Operators: Theory and Practice, Vol. 265, Springer Berlin, Heidelberg.

von Zedtwitz, M. (2002), “Organizational learning through post-project reviews in R \& D", $R$ and D Management, Vol. 32 No. 3, pp. 255-268.

Zien, K. and Buckler, S. (1997), "From experience dreams to market: Crafting a culture of innovation", Journal of Product Innovation Management, Vol. 14 No. 97, pp. 274-287. 